\title{
Articles
}

\section{Processed meat intake and incidence of Type 2 diabetes in younger and middle-aged women}

\author{
M. B. Schulze ${ }^{1}$, J. E. Manson ${ }^{2,3,4}$, W. C. Willett ${ }^{1,2,3}$, F. B. Hu${ }^{1,2,3}$ \\ ${ }^{1}$ Department of Nutrition, Harvard School of Public Health, Boston, Massachusetts \\ 2 Department of Epidemiology, Harvard School of Public Health, Boston, Massachusetts \\ ${ }^{3}$ Channing Laboratory, Department of Medicine, Brigham and Women's Hospital and Harvard Medical School, Boston, \\ Massachusetts \\ ${ }^{4}$ Division of Preventive Medicine, Department of Medicine, Brigham and Women's Hospital and Harvard Medical School, \\ Boston, Massachusetts
}

\section{Abstract}

Aim/hypothesis. The aim of this study was to investigate the association between processed and other meat intake and incidence of Type 2 diabetes in a large cohort of women.

Methods. Incident cases of Type 2 diabetes were identified during 8 years of follow-up in a prospective cohort study of 91246 U.S. women aged 26 to 46 years and being free of diabetes and other major chronic diseases at baseline in 1991.

Results. We identified 741 incident cases of confirmed Type 2 diabetes during 716276 person-years of follow-up. The relative risk adjusted for potential nondietary confounders was 1.91 (95\% CI: $1.42-2.57)$ in women consuming processed meat five times or more a week compared with those consuming processed meat less than once a week $(p<0.001$ for trend). Further adjustment for intakes of magnesium, cereal fibre, glycaemic index, and caffeine or for a Western di- etary pattern did not appreciably change the results and associations remained strong after further adjustment for fatty acid and cholesterol intake. Frequent consumption of bacon, hot dogs, and sausage was each associated with an increased risk of diabetes. While total red meat (beef or lamb as main dish, pork as main dish, hamburger, beef, pork or lamb as sandwich or mixed dish) intake was associated with an increased risk of diabetes, this association was attenuated after adjustment for magnesium, cereal fiber, glycaemic index, and caffeine (relative risk: $1.44 ; 95 \% \mathrm{CI}$ : 0.92-2.24).

Conclusion/interpretation. Our data suggest that diets high in processed meats could increase the risk for developing Type 2 diabetes. [Diabetologia (2003) 46: 1465-1473]

Keywords Diabetes mellitus, non-insulin-dependent, meat, meat products, risk factors, prospective studies, body mass index, incidence, questionnaires, nitrites.
Type 2 diabetes mellitus affects about 17 million US Americans $[1,2]$ and its prevalence has increased rapidly during the last decades $[2,3,4]$. In 2000, about 1 million US Americans have been newly diagnosed with diabetes $[1,2]$. Diabetes adversely affects the quality of life of individuals and has indirect effects on morbidity and mortality due to its complications,

Received: 12 May 2003 / Revised: 21 July 2003

Published online: 24 October 2003

(C) Springer-Verlag 2003

Corresponding author: M. B. Schulze, Department of Nutrition, Harvard School of Public Health, Boston, Massachusetts

E-mail: mschulze@hsph.harvard.edu

Abbreviations: RR, relative risk. particularly cardiovascular disease [5]. About 1.4 million disability-adjusted life years were lost in the US and Canada in 2001 due to diabetes [6]. In addition, diabetes mellitus is an enormous economic burden. Direct medical expenditures for diabetes care, chronic complications attributable to diabetes, and for the excess prevalence of general medical conditions alone totalled \$91.8 billion in the United States in 2002 [7]. While lifestyle characteristics such as obesity [8] and sedentary behaviour $[9,10]$ are established as risk factors for this disease [11], less is known about dietary factors [12].

Recent evidence from the Health Professionals Follow-up Study suggests a positive association between intake of processed meat and the risk of Type 2 diabe- 
tes [13]. There are several potential explanations for the observed association. Higher amounts of saturated fat and cholesterol in processed meats could increase risk of diabetes. Other components of red and processed meats, typically administered or developed in processing and preparation, such as nitrites and advanced glycation end-products (AGE), are also potential mediators [13, 14]. However, the increased risk with higher meat intake observed in previous studies might be due to dietary factors associated with meat intake other than fatty acids, nitrites, and nitrosamines. In particular, adherence to a "Western" dietary pattern is characterized by high intakes of red and processed meat $[15,16]$ and this dietary pattern [17] as well as other components of it, such as refined grains, snacks, sweets, French fries, and pizza [18, 19, 20] have been associated with diabetes risk as well. Therefore, it is not clear whether the observed associations were independent of the "Western" dietary pattern. We therefore examined the association between meat intake and risk of diabetes in a large cohort of young and middle-aged women, controlling for potentially confounding lifestyle characteristics as well as specific nutrients, particularly fatty acids, and dietary patterns.

\section{Subjects and methods}

Study population. The Nurses' Health Study II is a prospective cohort study of 116671 female US nurses. Participants were 24 to 44 years of age at study initiation in 1989 . This cohort is followed using biennial mailed questionnaires with a follow-up rate exceeding $90 \%$ for every 2 -year period and we estimate that there is almost complete $(98 \%)$ ascertainment of mortality. For the analyses presented here, women were excluded from the baseline population if they did not complete a dietary questionnaire in 1991 or if more than nine items were left blank on it, if the reported dietary intake was implausible with regard to total energy intake (i.e., $<500 \mathrm{kcal} /$ day or $>3500 \mathrm{kcal} /$ day), if they had a history of diabetes, cancer (except non-melanoma skin cancer) or cardiovascular disease reported on either the 1989 or 1991 questionnaire, or if they had no data on physical activity in 1991. These exclusions left a total of 91246 women for the analyses. The study was approved by the institutional review boards at the Harvard School of Public Health and the Brigham and Women's Hospital; completion of the self-administered questionnaire was considered to imply informed consent.

Dietary assessment. In 1991 the mailed questionnaire included a 133-food item semi-quantitative food frequency questionnaire to obtain dietary information. Women were asked how often they had consumed a commonly used unit or portion size of each food on average over the previous year. Questionnaire items on processed meat consumption included "bacon", "hot dogs", and "sausage, salami, bologna, and other processed meats" and items on red meat consumption included "beef or lamb as main dish", "pork as main dish", "hamburger", and "beef, pork, or lamb as a sandwich or mixed dish". There were nine possible responses, ranging from "never" to "six or more times per day" which were aggregated into four categories for the overall food groups red and processed meat (less than once per week, once per week, two to four times per week, five or more times per week). Single meat items were categorized into three categories (less than once per week, once per week, two or more times per week) due to the small number of subjects with frequent intake. The categorization was similar to the one previously used by our group in the Health Professionals Follow-up Study [13]. A similar questionnaire was used to update dietary information in 1995. Nutrient intakes were computed by multiplying the frequency response by the nutrient content of the specified portion sizes. Values for nutrients were derived from the US Department of Agriculture sources [21] and supplemented with information from manufacturers. The dietary glycaemic index (based on glucose as a standard) and intakes of dietary fibre, magnesium, and caffeine were energy-adjusted using the residuals method [22]. Intakes of fatty acids were expressed as nutrient density (\% of total energy intake) [22]. The validity and reliability of food frequency questionnaires similar to those used in the Nurses' Health Study II have been described elsewhere $[23,24]$. Briefly, the corrected correlation coefficients between FFQ and multiple dietary records were 0.56 for hot dogs, 0.70 for bacon, 0.55 for other processed meats, 0.38 for hamburgers, 0.46 for red meat as a main dish or mixed dish, 0.58 for poultry, and 0.66 for fish [23].

Ascertainment of Type 2 diabetes. Women reporting a new diagnosis of diabetes on any of the biennial questionnaires were sent supplementary questionnaires asking about diagnosis, treatment, and history of ketoacidosis to confirm the self-report and to distinguish between Type 1 and Type 2 diabetes. In accordance with the criteria of the National Diabetes Data Group [25] confirmation of diabetes required at least one of the following: (i) an elevated plasma glucose concentration (fasting plasma glucose $\geq 7.8 \mathrm{mmol} / \mathrm{l}$, random plasma glucose $\geq 11.1 \mathrm{mmol} / \mathrm{l}$, and/or plasma glucose $\geq 11.1 \mathrm{mmol} / \mathrm{l}$ after $\geq 2 \mathrm{~h}$ during OGTT) plus at least one classic symptom (excessive thirst, polyuria, weight loss, or hunger); (ii) no symptoms, but at least two elevated plasma glucose concentrations (by the above criteria) on different occasions; or (iii) treatment with hypoglycaemic medication (insulin or oral hypoglycaemic agent). We used the National Diabetes Data Group criteria to define diabetes because the majority of our cases were diagnosed prior to the release of the American Diabetes Association criteria in 1997 [26]. In substudies of the Nurses' Health Study I and the Health Professionals Follow-up Study, two similar cohort studies among medical professionals, $98 \%$ and $97 \%$ of the self-reported diabetes cases by using the same supplementaryquestionnaire were confirmed by medical record review $[27,28]$.

Assessment of non-dietary exposures. Information on age, weight, smoking status, contraceptive use, post-menopausal hormone replacement therapy, history of high blood pressure, and history of high blood cholesterol was collected by biennial questionnaires. We calculated BMI as the ratio of weight (in $\mathrm{kg}$ ) to squared height (in $\mathrm{m}^{2}$ ) the latter being assessed at baseline only. Self-reports of body weight have been shown to be highly correlated with technician-measured weights $(r=0.96)$ in the Nurses' Health Study I [29]. Family history of diabetes was reported 1989 only. Physical activity was assessed with the 1991 and 1997 questionnaires and was computed as metabolic equivalents per week using the duration per week of various forms of exercise, weighting each activity by its intensity level. Correlations between physical activity reported on recalls and diaries and that reported on the questionnaire were high (0.79 and 0.62) [30].

Statistical analysis. We estimated the relative risk (RR) for each category of intake compared to the lowest category using 
Cox proportional hazards analysis stratified on 5-year age categories. Participants who were diagnosed with diabetes (Type 1 or Type 2) or who died during follow-up were censored at the date of diagnosis or death. The 1991 intake was used for the follow-up between 1991 and 1995, and the average of the 1991 and 1995 intakes for the follow-up between 1995 and 1999 to reduce within-subject variation and best represent long-term diet [31]. We used only the 1991 but not the 1995 intake data for those individuals who reported on the 1993 or 1995 questionnaire a diagnosis of cancer (except non-melanoma skin cancer) or cardiovascular disease because changes in diet after development of these conditions might confound the relationship between dietary intake and diabetes [31].

We used confirmatory factor analysis to test whether a twopattern structure, which has been repeatedly reported from the Nurses' Health Study I and the Health Professionals Follow-up Study $[15,16,17,32,33,34,35]$, does represent an acceptable model of the data [36]. The Goodness-of-fit of the proposed structure was determined by the Goodness-of-Fit Index [37], the Non-normed-Fit Index [38], the Comparative Fit Index [39], the Root Mean Square Error of Approximation [40], and by the significance-of-factor loadings. A pattern structure, representing one pattern (labelled "Western") associated with higher intakes of red meat, processed meat, refined grain products, snacks, sweets and deserts, French fries, and pizza and another pattern (labelled "Prudent") associated with higher intakes of fruits, tomatoes, cabbages, green leafy vegetables, dark yellow vegetables, legumes, other vegetables, poultry, and fish satisfied these assumptions. We calculated patterns scores for each individual by summing the standardized food intakes (standardizing to mean zero and standard deviation one) for each pattern. This method has been shown to lead only to a minor loss of information compared to the more common determination of factor scores in exploratory [41] and confirmatory factor analysis [42] that incorporate weights corresponding to the observed factor loadings.

We used information on covariates obtained from the baseline or subsequent questionnaires in multivariate analyses, including BMI $(<21.0,21.0-22.9,23.0-24.9, \quad 25.0-26.9$, $27.0-28.9,29.0-30.9,31.0-32.9,33.0-34.9$, $\geq 35.0)$, total caloric intake (quintiles), alcohol intake (0, 0.1-4.9, 5.0-9.9, $10+\mathrm{g} / \mathrm{d}$ ), physical activity (quintiles), family history of diabetes (yes, no), smoking (never, past, current), history of high blood pressure (yes, no), history of high blood cholesterol (yes, no), post-menopausal hormone use (never, ever), oral contraceptive use (never, past, current), magnesium intake (quintiles), glycaemic index (quintiles), cereal fibre intake (quintiles), caffeine intake (quintiles), types of fatty acids (quintiles), cholesterol intake (quintiles), and dietary patterns (quintiles). Non-dietary covariates were updated during follow-up using the most recent data for each 2-year follow-up interval.

The significance of linear trends across categories of dietary intake was tested by assigning each participant the median value for the category and modeling this value as a continuous variable. We also tested for effect modification by BMI and glycaemic index by performing stratified analyses by these variables adjusting for lifestyle, including BMI as continuous variable in models for BMI strata, as well as dietary variables and by modeling interaction terms. A $p$ value of less than 0.05 was considered statistically significant. All statistical analyses were performed using SAS statistical software (SAS Institute Inc, Cary, N.C., USA).

\section{Results}

During 716276 person-years of follow-up, we documented 741 new cases of Type 2 diabetes. Among the study population of 91246 women, a higher intake of processed and red meat was related to higher BMI and lower physical activity and higher prevalences of smoking, family history of diabetes, and history of hypertension (Table 1). In addition, women with higher processed and red meat intakes had higher intakes of total energy and fat, and a higher "Western" pattern score and had lower intakes of carbohydrates, magnesium, and cereal fibre.

Increasing processed meat intake was strongly associated with progressively higher risk for Type 2 diabetes (Table 2). The age-adjusted RR was 4.55 (95\% CI: 3.44-6.01) for women consuming processed meat five times or more a week compared with those consuming processed meat less than once a week. This association was attenuated after adjustment for BMI, but still remained strong. Further adjustment for lifestyle covariates, such as alcohol consumption, smoking, and family history of diabetes, did not materially change this observation. The multivariate

RRs across frequencies of processed meat consumption (<1/week, 1/week, 2-4/week, and $\geq 5 /$ week) were $1.00,1.16$ (95\% CI: 0.97-1.39), 1.44 (95\% CI: $1.14-1.82)$, and 1.91 (95\% CI: $1.42-2.57)(p<0.001$ for trend). Further adjustment for cereal fibre, glycaemic index, magnesium, and caffeine or for the "Western" dietary pattern did not appreciably change these results. We additionally adjusted for fruit fibre, vegetable fibre, and folate intake in the multivariate and nutrient adjusted model and for regular and diet carbonated soft drink consumption in the multivariate and pattern-adjusted model, but results remained unchanged. Furthermore, processed meat consumption remained strongly associated with diabetes risk after adding intakes of specific fatty acids and cholesterol to the multivariate and nutrient-adjusted model. Similarly, single food items (bacon, hot dogs and sausage, salami, and bologna) showed positive associations with risk of diabetes.

In age-adjusted analysis, total red meat intakes as well as intake of hamburgers, beef or lamb as a main dish, pork as a main dish, and beef, lamb, or pork as a sandwich or mixed dish were positively associated with risk of Type 2 diabetes (Table 3). These associations were attenuated after adjusting for BMI. The multivariate RRs across categories of total red meat consumption (<1/week, 1/week, 2-4/week, and $\geq 5 /$ week) were $1.00,1.19$ (95\% CI: 0.79-1.80), 1.38 (95\% CI: 0.91-2.09), and 1.58 (95\% CI: $1.03-2.42$ ) ( $p=0.003$ for trend). Total red meat intake was associated with only a modest and non-significant increase of diabetes risk (RR for extreme categories: 1.44; $95 \%$ CI: 0.92-2.24) in multivariate analysis after additional adjustment for magnesium, glycaemic index, cereal fibre, and caffeine. Further adjustment for fatty acid and cholesterol intake further attenuated the association. Among the different sources of red meat, beef as main dish and hamburgers were associated with increased 
Table 1. Age-standardized baseline characteristics according to frequency of processed meat and red meat intake in 91246 women

\begin{tabular}{|c|c|c|c|c|c|c|c|c|}
\hline \multirow[b]{2}{*}{ Variable } & \multicolumn{4}{|c|}{ Frequency of processed meat consumption } & \multicolumn{4}{|c|}{ Frequency of red meat consumption } \\
\hline & $<1 /$ wk & $1 / \mathrm{wk}$ & $2-4 / w k$ & $\geq 5 / \mathrm{wk}$ & $<1 /$ wk & $1 / \mathrm{wk}$ & $2-4 / w k$ & $\geq 5 / w k$ \\
\hline BMI $\left(\mathrm{kg} / \mathrm{m}^{2}\right)$, mean ${ }^{\mathrm{a}}$ & 23.9 & 24.8 & 25.3 & 26.2 & 23.1 & 24.1 & 24.8 & 25.6 \\
\hline Physical activity, mean ${ }^{\mathrm{b}}$ & 24.9 & 18.9 & 17.9 & 16.8 & 31.4 & 22.3 & 18.7 & 17.5 \\
\hline Currently smoking, $\%$ & 9.6 & 13.1 & 14.7 & 16.4 & 8.3 & 11.2 & 12.9 & 14.4 \\
\hline History of high blood cholesterol, \% & 9.7 & 9.0 & 9.2 & 9.7 & 8.6 & 9.2 & 9.3 & 9.8 \\
\hline Currently using oral contraceptives, $\%$ & 11.3 & 10.6 & 10.0 & 9.8 & 11.1 & 11.4 & 10.2 & 10.3 \\
\hline $\begin{array}{l}\text { Currently receiving hormone } \\
\text { replacement therapy, \% }\end{array}$ & 2.4 & 2.5 & 2.6 & 2.4 & 2.6 & 2.3 & 2.6 & 2.6 \\
\hline \multicolumn{9}{|l|}{ Diet, mean } \\
\hline Saturated fat, energy percentage & 10.2 & 11.6 & 12.2 & 12.8 & 9.0 & 10.7 & 11.6 & 12.5 \\
\hline Monounsaturated fat, energy percentage & 10.8 & 12.4 & 13.1 & 13.9 & 9.5 & 11.2 & 12.4 & 13.6 \\
\hline Polyunsaturated fat, energy percentage & 5.5 & 5.7 & 5.8 & 5.9 & 5.6 & 5.6 & 5.7 & 5.6 \\
\hline Trans fat, energy percentage & 1.4 & 1.7 & 1.8 & 1.9 & 1.2 & 1.6 & 1.7 & 1.8 \\
\hline Cholesterol, mg/d & 227 & 247 & 257 & 266 & 194 & 234 & 247 & 268 \\
\hline Magnesium, mg/d & 341 & 305 & 292 & 281 & 377 & 326 & 304 & 288 \\
\hline Caffeine, $\mathrm{mg} / \mathrm{d}$ & 237 & 246 & 246 & 255 & 223 & 246 & 244 & 244 \\
\hline Glycaemic index & 53.5 & 54.0 & 54.3 & 54.5 & 53.0 & 53.6 & 54.1 & 54.4 \\
\hline Cereal fibre, $g$ & 6.4 & 5.3 & 5.0 & 4.7 & 7.6 & 6.0 & 5.3 & 4.7 \\
\hline Western pattern score & -2.12 & 0.13 & 2.50 & 5.53 & -3.31 & -1.62 & 0.36 & 3.02 \\
\hline Prudent pattern score & 0.27 & -0.51 & -0.28 & 0.07 & 1.18 & -0.46 & -0.34 & 0.12 \\
\hline
\end{tabular}

a BMI was calculated as weight in kilograms divided by the square of the height in metres

risk after multivariate adjustment, but not pork as main dish and beef, pork, or lamb as a sandwich or mixed dish. After adjustment for nutrient intakes, only hamburgers remained positively associated.

We furthermore tested whether poultry and fish intakes were associated with risk of Type 2 diabetes. No significant associations were observed for fish (multivariate-adjusted $R R$ for intake $\geq 2 /$ week vs. $<1$ /week: 1.04; 95\% CI: $0.82-1.32 ; p=0.87$ for trend), however, more frequent poultry intake was associated with a moderately decreased risk of diabetes. The multivariate-adjusted RRs across categories of poultry intake ( $\leq 1$ /week, $2-4 /$ week, and $\geq 5 /$ week) were $1.00,0.87$ (95\% CI: 0.74-1.02), and 0.78 (95\% CI: 0.62-0.98) ( $p=0.017$ for trend). Further adjustment for nutrient intake or the "Prudent" dietary pattern did not materially change this result.

We furthermore tested for modification of effects of processed meat intake by BMI and glycaemic index by carrying out stratified analyses. While more frequent intake of processed meat appeared to be associated with a higher risk of diabetes in women with BMI greater than or equal to 30 (multivariate-adjusted RR for intake $\geq 2 /$ week vs. <1/week: $1.44 ; 95 \%$ CI: b Physical activity was computed as metabolic equivalents per week using the duration per week of various forms of exercise, weighting each activity by its intensity level

1.08-1.90) compared to women with BMI less than 30 (multivariate-adjusted RR: 1.14 ; 95\% CI: $0.72-1.82$ ), the test for interaction was not significant $(p=0.34)$. In addition, no effect modification by glycaemic index, which was dichotomized based on the population median for the 1991 FFQ (median=54), was observed ( $p=0.68$ for interaction).

\section{Conclusion}

In this 8-year follow-up study of 91246 female nurses, we found a positive association between processed meat intake and risk of Type 2 diabetes, independent of known risk factors including other measured dietary variables. In addition, high intakes of red meat were associated with an increased risk of diabetes.

Our data are broadly consistent with those observed among older participants in the Health Professionals Follow-up Study [13] and the Nurses' Health Study I [18]. The RR comparing men with processed meat intakes greater than or equal to five per week to those men with intakes less than one per month was 1.46 (95\% CI: $1.14-1.86, p<0.001$ for trend) in the Health 
Table 2. Relative risks (RR) of Type 2 diabetes according to frequencies of processed meat intake in 91246 women

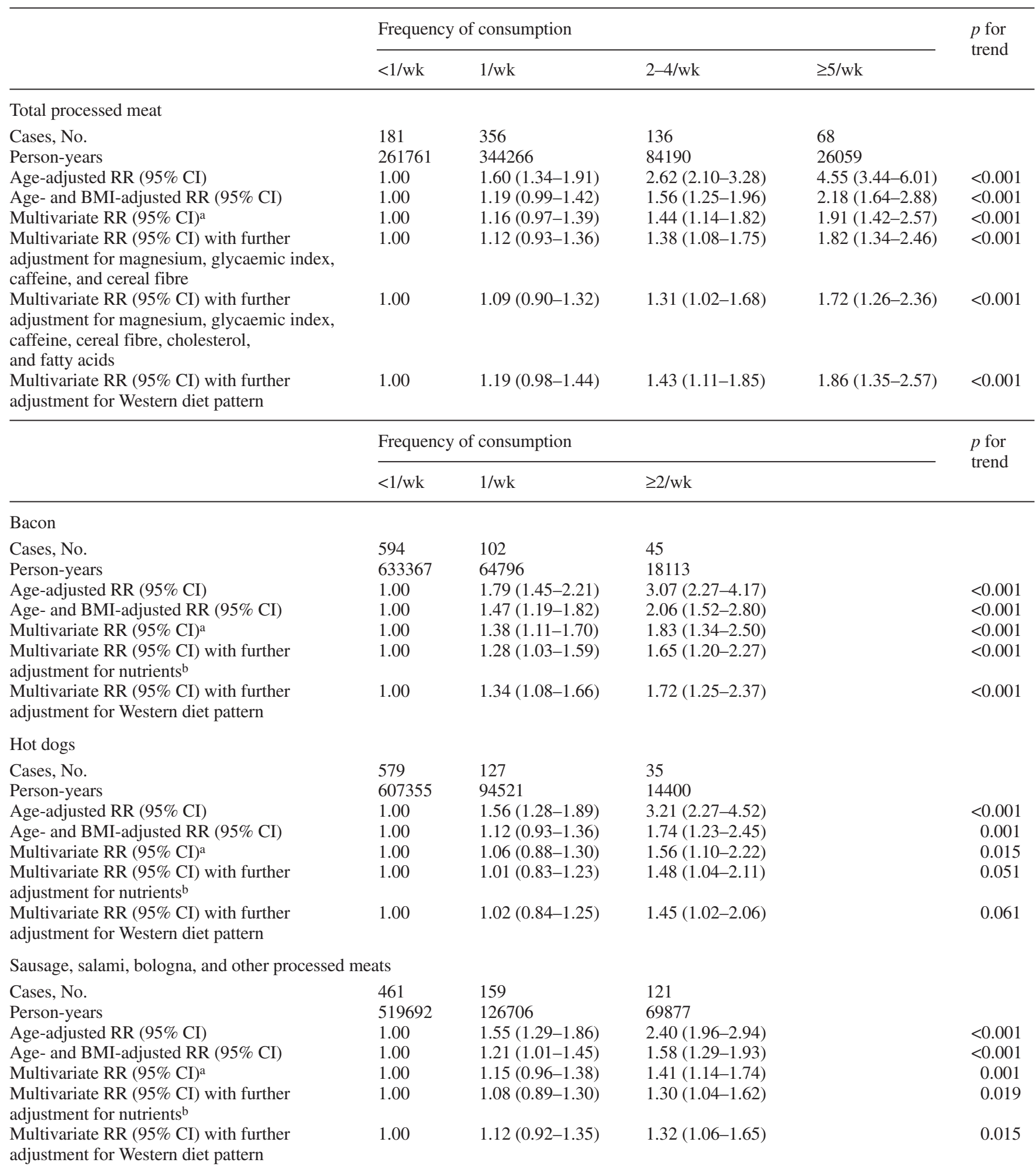

a RRs (95\% CI) adjusted for age, BMI (9 categories), calories (quintiles), alcohol $(0,0.1-4.9,5.0-9.9,10+\mathrm{g} / \mathrm{d})$, physical activity (quintiles), family history of diabetes, smoking (never, past, current), history of high blood pressure, history of high blood cholesterol, post menopausal hormone use (never, ever), and oral contraceptive use (never, past, current) b Multivariate model with additional adjustment for intake (quintiles) of cereal fibre, magnesium, caffeine, glycaemic index, saturated fat, monounsaturated fat, polyunsaturated fat, trans fat, and cholesterol 
Table 3. Relative risks (RR) of Type 2 diabetes according to frequencies of red meat intake in 91296 women

\begin{tabular}{|c|c|c|c|c|c|}
\hline & \multicolumn{4}{|c|}{ Frequency of consumption } & \multirow{2}{*}{$\begin{array}{l}p \text { for } \\
\text { trend }\end{array}$} \\
\hline & $<1 /$ wk & $1 / \mathrm{wk}$ & $2-4 / w k$ & $\geq 5 / \mathrm{wk}$ & \\
\hline \multicolumn{6}{|l|}{ Total red meat } \\
\hline Cases, No. & 25 & 218 & 263 & 235 & \\
\hline Person-years & 56228 & 286500 & 234137 & 139412 & \\
\hline Age-adjusted RR (95\% CI) & 1.00 & $1.78(1.18-2.69)$ & $2.58(1.71-3.89)$ & $4.06(2.69-6.14)$ & $<0.001$ \\
\hline Age- and BMI-adjusted RR (95\% CI) & 1.00 & $1.22(0.80-1.84)$ & $1.44(0.96-2.18)$ & $1.78(1.18-2.69)$ & $<0.001$ \\
\hline Multivariate RR $(95 \% \mathrm{CI})^{\mathrm{a}}$ & 1.00 & $1.19(0.79-1.80)$ & $1.38(0.91-2.09)$ & $1.58(1.03-2.42)$ & 0.003 \\
\hline $\begin{array}{l}\text { Multivariate RR ( } 95 \% \mathrm{CI}) \text { with further } \\
\text { adjustment for magnesium, glycaemic index, } \\
\text { caffeine, and cereal fibre }\end{array}$ & 1.00 & $1.16(0.76-1.77)$ & $1.30(0.85-1.99)$ & $1.44(0.92-2.24)$ & 0.036 \\
\hline $\begin{array}{l}\text { Multivariate RR ( } 95 \% \mathrm{CI}) \text { with further } \\
\text { adjustment for magnesium, glycaemic index, } \\
\text { caffeine, cereal fibre, cholesterol, } \\
\text { and fatty acids }\end{array}$ & 1.00 & $1.11(0.72-1.70)$ & $1.19(0.76-1.86)$ & $1.26(0.78-2.04)$ & 0.269 \\
\hline \multirow{3}{*}{$\begin{array}{l}\text { Multivariate RR }(95 \% \mathrm{CI}) \text { with further } \\
\text { adjustment for Western diet pattern }\end{array}$} & 1.00 & $1.24(0.82-1.89)$ & $1.44(0.94-2.23)$ & $1.59(1.01-2.49)$ & 0.019 \\
\hline & \multicolumn{4}{|c|}{ Frequency of consumption } & \multirow{2}{*}{$\begin{array}{l}p \text { for } \\
\text { trend }\end{array}$} \\
\hline & $<1 /$ wk & $1 / \mathrm{wk}$ & $\geq 2 / \mathrm{wk}$ & & \\
\hline \multicolumn{6}{|l|}{ Beef or lamb as a main dish } \\
\hline Cases, No. & 269 & 239 & 233 & & \\
\hline Person-years & 308758 & 184283 & 223234 & & \\
\hline Age-adjusted RR (95\% CI) & 1.00 & $1.43(1.20-1.70)$ & $2.11(1.71-2.62)$ & & $<0.001$ \\
\hline Age- and BMI-adjusted RR (95\% CI) & 1.00 & $1.15(0.97-1.37)$ & $1.45(1.17-1.80)$ & & 0.001 \\
\hline Multivariate RR $(95 \% \mathrm{CI})^{\mathrm{a}}$ & 1.00 & $1.12(0.94-1.34)$ & $1.33(1.06-1.65)$ & & 0.021 \\
\hline $\begin{array}{l}\text { Multivariate RR }(95 \% \mathrm{CI}) \text { with further } \\
\text { adjustment for nutrients }\end{array}$ & 1.00 & $1.03(0.86-1.24)$ & $1.11(0.87-1.42)$ & & 0.41 \\
\hline $\begin{array}{l}\text { Multivariate RR }(95 \% \mathrm{CI}) \text { with further } \\
\text { adjustment for Western diet pattern }\end{array}$ & 1.00 & $1.11(0.93-1.34)$ & $1.28(1.02-1.61)$ & & 0.052 \\
\hline \multicolumn{6}{|l|}{ Pork as a main dish } \\
\hline Cases, No. & 518 & 192 & 31 & & \\
\hline Person-years & 520361 & 176409 & 19505 & & \\
\hline Age-adjusted RR (95\% CI) & 1.00 & $1.19(1.01-1.40)$ & $1.96(1.36-2.82)$ & & $<0.001$ \\
\hline Age- and BMI-adjusted RR (95\% CI) & 1.00 & $1.07(0.91-1.27)$ & $1.46(1.02-2.11)$ & & 0.035 \\
\hline Multivariate RR $(95 \% \mathrm{CI})^{\mathrm{a}}$ & 1.00 & $1.04(0.87-1.23)$ & $1.20(0.82-1.74)$ & & 0.33 \\
\hline $\begin{array}{l}\text { Multivariate RR }(95 \% \mathrm{CI}) \text { with further } \\
\text { adjustment for nutrients }\end{array}$ & 1.00 & $0.95(0.80-1.13)$ & $1.01(0.69-1.48)$ & & 0.91 \\
\hline $\begin{array}{l}\text { Multivariate RR }(95 \% \mathrm{CI}) \text { with further } \\
\text { adjustment for Western diet pattern }\end{array}$ & 1.00 & $1.02(0.85-1.20)$ & $1.14(0.78-1.66)$ & & 0.51 \\
\hline \multicolumn{6}{|l|}{ Hamburgers } \\
\hline Cases, No. & 288 & 316 & 137 & & \\
\hline Person-years & 379956 & 265572 & 70749 & & \\
\hline Age-adjusted RR (95\% CI) & 1.00 & $1.80(1.53-2.11)$ & $3.46(2.80-4.27)$ & & $<0.001$ \\
\hline Age- and BMI-adjusted RR (95\% CI) & 1.00 & $1.28(1.09-1.50)$ & $1.70(1.38-2.11)$ & & $<0.001$ \\
\hline Multivariate RR $(95 \% \mathrm{CI})^{\mathrm{a}}$ & 1.00 & $1.19(1.01-1.41)$ & $1.48(1.18-1.85)$ & & 0.001 \\
\hline $\begin{array}{l}\text { Multivariate RR }(95 \% \mathrm{CI}) \text { with further } \\
\text { adjustment for nutrients }\end{array}$ & 1.00 & $1.12(0.94-1.34)$ & $1.34(1.05-1.70)$ & & 0.026 \\
\hline $\begin{array}{l}\text { Multivariate RR ( } 95 \% \text { CI) with further } \\
\text { adjustment for Western diet pattern }\end{array}$ & 1.00 & $1.18(0.99-1.40)$ & $1.41(1.10-1.79)$ & & 0.010 \\
\hline \multicolumn{6}{|l|}{ Beef, pork, or lamb as a sandwich or mixed dish } \\
\hline Cases, No. & 287 & 292 & 162 & & \\
\hline Person-years & 326788 & 259683 & 129805 & & \\
\hline Age-adjusted RR (95\% CI) & 1.00 & $1.34(1.14-1.57)$ & $1.66(1.36-2.01)$ & & $<0.001$ \\
\hline
\end{tabular}


Table 3. (continued)

\begin{tabular}{|c|c|c|c|c|}
\hline & \multicolumn{3}{|c|}{ Frequency of consumption } & \multirow{2}{*}{$\begin{array}{l}p \text { for } \\
\text { trend }\end{array}$} \\
\hline & $<1 /$ wk & $1 / \mathrm{wk}$ & $\geq 2 / \mathrm{wk}$ & \\
\hline Multivariate RR $(95 \% \mathrm{CI})^{\mathrm{a}}$ & 1.00 & $1.05(0.89-1.24)$ & $1.03(0.83-1.27)$ & 0.89 \\
\hline $\begin{array}{l}\text { Multivariate RR }(95 \% \mathrm{CI}) \text { with further } \\
\text { adjustment for nutrients }\end{array}$ & 1.00 & $0.97(0.81-1.15)$ & $0.89(0.71-1.11)$ & 0.31 \\
\hline
\end{tabular}

a and ${ }^{b}$ : see Table 2

Professionals Follow-up Study. However, no associations between red meat and poultry intake and risk of diabetes were observed. Similarly, intake of processed meat, but not other meats, was associated with diabetes risk in the Nurses' Health Study I, an analysis in which 61 food items were simultaneously modelled controlling for BMI, alcohol intake, energy intake, and prior weight change. In another study, diabetes prevalence and incidence (based on death certificates) was higher with higher intakes of total meat [43]. The majority of our cases were diagnosed after 40 years of age $(79 \%)$ and therefore do not represent cases of early-onset diabetes mellitus, and given the similar results observed in the Health Professionals Follow-up Study, a cohort of substantially older men (40-75 years at baseline), it seems unlikely that our observations apply to younger individuals or women only.

The positive associations between processed meat intake and risk of diabetes that we observed were largely independent of the intake of magnesium, glycaemic index, cereal fibre, fruit fibre, vegetable fibre, folate, and caffeine that might be associated with processed meat intake. Furthermore, the Western pattern, which is characterized by high intakes of red and processed meat $[15,16]$ and which has been associated with diabetes risk [17], did not account for the association observed. The association remained strong after further adjustment for dietary fatty acids and cholesterol. These results indicate that components of processed meat, other than fatty acids and cholesterol, might be relevant in the development of diabetes. Several possible pathways have been proposed in this context. One pathway links nitrites, frequently used for conservation of processed meats, via a possible beta-cell toxic effect of nitrosamines. Nitrosamines can be formed by interaction of amino compounds with nitrites either in the stomach or already within the food product [44]. They have been found to be beta-cell toxic as well as to be associated with an increased risk of Type 1 diabetes [45]. In addition, low doses of the nitrosamine streptozotocin were found to induce Type 2 diabetes in animal models [46, 47]. Another potential pathway is characterized by toxic effects of AGE [14]. Here, animal models and human studies suggest that AGE could be involved in the pro- gression of Type 2 diabetes. The development of Type 2 diabetes was reduced by treatment with aminoguanidine, an AGE inhibitor, in genetically diabetic mice [48] and improvement of various features of insulin resistance was shown in mice fed a diet low in AGE [49]. In addition, a diet high in AGE was found to promote inflammatory mediators that might be important in the genesis of diabetes, such as vascular adhesion molecule-1, tumour necrosis factor-alpha, and C-reactive protein, in a study among 24 diabetic subjects [50]. AGE levels might be particularly high in those animal foods which are high in protein and fat [51] and which are processed [14]. Furthermore, there is an indication that higher iron stores resulting from frequent meat intake might impair insulin sensitivity [52]. This hypothesis is supported by cross-sectional [53] and cohort studies [54], where higher iron stores were associated with higher blood glucose concentrations and higher risk of diabetes. Furthermore, animal studies suggest that iron depletion enhances glucose disposal $[55,56]$. In addition, high meat consumption might be associated with an overall high-protein diet. Although stimulation of insulin and glucagon secretion counterbalances the increased gluconeogenesis due to postprandial amino acid elevations, the gluconeogenetic effect of amino acids might be substantial in subjects with impaired insulin secretion [57]. While this pathway might in part explain the effect of red meat consumption in our study, it is not likely to explain the effect observed for processed meats, because their consumption was not positively associated with total protein intake.

BMI accounted for a large part of the observed associations between red and processed meat intake and risk of diabetes. We divided the BMI into nine categories to properly control for its confounding effects, and results were similar using the continuous BMI instead (data not shown). However, body fat distribution, besides body size, is an important determinant of insulin sensitivity as well [28] and might therefore represent a potential confounder. Although the results were similar after additionally controlling for waist-to-hip-ratio in a separate analysis among 43755 women who reported waist and hip circumferences in 1993 (data not shown), residual confounding by body fat might still 
have biased our observations, even though this seems to be unlikely. In addition, while we adjusted for a history of high blood cholesterol and hypertension in our analysis, we were not able to control in more detail for dyslipoproteinaemia or other potential confounding measures of the metabolic syndrome. Misclassification of disease status should not have biased our observations. We have previously reported that almost $100 \%$ of cases identified based on self-reports on a validated extended questionnaire were confirmed by a medical record review [27, 28]. Diagnostic criteria for Type 2 diabetes changed after the time most women in this cohort were diagnosed [26], so that some women classified as non-diabetic would now be considered cases; however, this would not affect the validity of the findings. While screening bias, i.e., greater screening for Type 2 diabetes in women with high processed meat intake, might contribute to the observed results, we consider this an unlikely explanation. It is possible that women with high processed meat intake have seen a physician more frequently because these women tended to have higher BMI and a higher prevalence of high blood pressure. However, most women in this cohort of health professionals received routine health care, and associations remained strong after controlling for $\mathrm{BMI}$ and history of high blood pressure. Imprecise dietary measurement and residual confounding are possible alternative explanations for some of the observed associations. However, errors in dietary assessment measures might have accounted for a lack of association but not the reverse [31]. The repeated dietary measurements made in this study were advantageous because they allowed for fewer measurement errors and changes in behavioural dietary patterns over time to be assessed [31]. Adjustment for the "Western" pattern might represent an overadjustment, since red and processed meats are components of the "Western" pattern. However, the main purpose for adjustment for the "Western" pattern in our analysis was to control for potential confounding by overall dietary patterns. Although red and processed meats are components of the pattern, other food items (refined grain, snacks, sweets, French fries, pizza) are important components as well. Adjustment for the "Western" pattern therefore controlled for potential confounding by these dietary variables. Since risk estimates were only very moderately attenuated adjusting for the "Western" pattern and remained unchanged after further adjustment for regular and diet carbonated soft drinks (which might contribute to AGE intake), it is unlikely that confounding by other food groups associated with red and processed meat intake explain our findings or that overadjustment is an important issue in their interpretation.

In conclusion, our findings support the hypothesis that diets high in processed meat increase risk of Type 2 diabetes. Since processed meats are associated with increased risk independent of underlying dietary patterns and nutrients, these data add to the concern that components of processed meats, such as nitrites and AGE, could increase the risk of Type 2 diabetes.

Acknowledgements. Funded by a research grant (CA50385) from the National Institutes of Health. Dr. Schulze was also supported by an European Association for the Study of Diabetes/American Diabetes Association Trans-Atlantic fellowship and a fellowship within the Programme of the German Academic Exchange Service (DAAD). We thank Dr. Camargo for his work related to the validation of diabetes self-reports in our cohort.

\section{References}

1. Centers for Disease Control and Prevention (2002) National diabetes fact sheet: general information and national estimates on diabetes in the United States, 2000. U.S. Department of Health and Human Services, Centers for Disease Control and Prevention, Atlanta, GA

2. Mokdad AH, Ford ES, Bowman BA et al. (2003) Prevalence of obesity, diabetes, and obesity-related health risk factors, 2001. JAMA 289:76-79

3. Mokdad AH, Ford ES, Bowman BA et al. (2000) Diabetes trends in the US: 1990-1998. Diabetes Care 23:1278-1283

4. Mokdad AH, Bowman BA, Ford ES, Vinicor F, Marks JS, Koplan JP (2001) The continuing epidemics of obesity and diabetes in the United States. JAMA 286:1195-1200

5. Cho E, Rimm EB, Stampfer MJ, Willett WC, Hu FB (2002) The impact of diabetes mellitus and prior myocardial infarction on mortality from all causes and from coronary heart disease in men. J Am Coll Cardiol 40:954-960

6. WHO (2002) The World Health Report 2002: reducing risks, promoting healthy life. WHO, Geneva

7. Anonymous (2003) Economic Costs of Diabetes in the US in 2002. Diabetes Care 26:917-932

8. Astrup A, Finer N (2000) Redefining type 2 diabetes: 'diabesity' or 'obesity dependent diabetes mellitus'? Obes Rev 1:57-59

9. Paffenbarger RS Jr, Lee IM, Kampert JB (1997) Physical activity in the prevention of non-insulin-dependent diabetes mellitus. World Rev Nutr Diet 82:210-218

10. Wei M, Schwertner HA, Blair SN (2000) The association between physical activity, physical fitness, and type 2 diabetes mellitus. Compr Ther 26:176-182

11. Hu FB, Manson JE, Stampfer MJ et al. (2001) Diet, lifestyle, and the risk of type 2 diabetes mellitus in women. $\mathrm{N}$ Engl J Med 345:790-797

12. Sherwin RS, Anderson RM, Buse JB et al. (2003) The prevention or delay of type 2 diabetes. Diabetes Care 26 (Suppl 1):S62-69

13. Dam RM van, Willett WC, Rimm EB, Stampfer MJ, Hu FB (2002) Dietary fat and meat intake in relation to risk of type 2 diabetes in men. Diabetes Care 25:417-424

14. Peppa M, Goldberg T, Cai W, Rayfield E, Vlassara H (2002) Glycotoxins: a missing link in the "Relationship of Dietary Fat and Meat Intake in Relation to Risk of Type 2 Diabetes in Men". Diabetes Care 25:1898-1899

15. Hu FB (2002) Dietary pattern analysis: a new direction in nutritional epidemiology. Curr Opin Lipidol 13:3-9

16. Schulze MB, Hu FB (2002) Dietary patterns and risk of hypertension, type 2 diabetes mellitus, and coronary heart disease. Curr Atheroscler Rep 4:462-467

17. van Dam RM, Rimm EB, Willett WC, Stampfer MJ, Hu FB (2002) Dietary patterns and risk for type 2 diabetes mellitus in U.S. men. Ann Intern Med 136:201-209 
18. Colditz GA, Manson JE, Stampfer MJ, Rosner B, Willett WC, Speizer FE (1992) Diet and risk of clinical diabetes in women. Am J Clin Nutr 55:1018-1023

19. Salmeron J, Ascherio A, Rimm EB et al. (1997) Dietary fiber, glycemic load, and risk of NIDDM in men. Diabetes Care 20:545-550

20. Salmeron J, Manson JE, Stampfer MJ, Colditz GA, Wing AL, Willett WC (1997) Dietary fiber, glycemic load, and risk of non-insulin-dependent diabetes mellitus in women. JAMA 277:472-477

21. US Department of Agriculture (1992) Composition of foods: raw, processed, prepared, 1963-1991. US Government Printing Office, Washington, DC

22. Willett WC, Stampfer M (1998) Implications of total energy intake for epidemiologic analysis. In: Willett WC (ed.) Nutritional epidemiology. Oxford University Press, New York, pp 273-301

23. Salvini S, Hunter DJ, Sampson L et al. (1989) Food-based validation of a dietary questionnaire: the effects of weekto-week variation in food consumption. Int $\mathrm{J}$ Epidemiol 18:858-867

24. Willett WC, Lenart E (1998) Reproducibility and validity of food-frequency questionnaires. In: Willett WC (ed.) Nutritional epidemiology. Oxford University Press, New York, pp 101-156

25. National Diabetes Data Group (1979) Classification and diagnosis of diabetes mellitus and other categories of glucose intolerance. Diabetes 28:1039-1057

26. Expert Committee on the Diagnosis and Classification of Diabetes Mellitus (1997) Report of the Expert Committee on the Diagnosis and Classification of Diabetes Mellitus. Diabetes Care 20:1183-1197

27. Manson JE, Rimm EB, Stampfer MJ et al. (1991) Physical activity and incidence of non-insulin-dependent diabetes mellitus in women. Lancet 338:774-778

28. Hu FB, Leitzmann MF, Stampfer MJ, Colditz GA, Willett WC, Rimm EB (2001) Physical activity and television watching in relation to risk for type 2 diabetes mellitus in men. Arch Intern Med 161:1542-1548

29. Willett W, Stampfer MJ, Bain C et al. (1983) Cigarette smoking, relative weight, and menopause. Am J Epidemiol 117:651-658

30. Wolf AM, Hunter DJ, Colditz GA et al. (1994) Reproducibility and validity of a self-administered physical activity questionnaire. Int J Epidemiol 23:991-999

31. Hu FB, Stampfer MJ, Rimm E et al. (1999) Dietary fat and coronary heart disease: a comparison of approaches for adjusting for total energy intake and modeling repeated dietary measurements. Am J Epidemiol 149:531-540

32. Hu FB, Rimm E, Smith-Warner SA et al. (1999) Reproducibility and validity of dietary patterns assessed with a foodfrequency questionnaire. Am J Clin Nutr 69:243-249

33. Hu FB, Rimm EB, Stampfer MJ, Ascherio A, Spiegelman D, Willett WC (2000) Prospective study of major dietary patterns and risk of coronary heart disease in men. Am J Clin Nutr 72:912-921

34. Fung TT, Rimm EB, Spiegelman D et al. (2001) Association between dietary patterns and plasma biomarkers of obesity and cardiovascular disease risk. Am J Clin Nutr 73:61-67

35. Fung TT, Willett WC, Stampfer MJ, Manson JE, Hu FB (2001) Dietary patterns and the risk of coronary heart disease in women. Arch Intern Med 161:1857-1862

36. Bentler PM (1980) Mutivariate analysis with latent variables: causal modeling. Annu Rev Psychol 31:11-21

37. Joreskog KG, Sorbom D (1986) LISREL VI: analysis of linear structural relationships by maximum likelihood, in- strumental variables, and least squares methods. University of Uppsala Department of Statistics, Uppsala, Sweden

38. Bentler PM, Bonett DG (1980) Significance tests and goodness of fit in the analysis of covariance structures. Psychol Bull 88:588-606

39. Bentler PM (1990) Comparative fit indexes in structural models. Psychometrika 107:238-246

40. Browne MW, Cudeck R (1993) Alternative ways of assessing model fit. In: Bollen KA, Long JS (eds) Testing structural equation models. Sage, Newbury Park, CA

41. Schulze MB, Hoffmann K, Kroke A, Boeing H (2003) An approach to construct simplified measures of dietary patterns from exploratory factor analysis. Br J Nutr 89: 409-419

42. Comrey AL (1988) Factor-analytic methods of scale development in personality and clinical psychology. J Consult Clin Psychol 56:754-761

43. Snowdon DA, Phillips RL (1985) Does a vegetarian diet reduce the occurrence of diabetes? Am J Public Health 75:507-512

44. Lijinsky W (1999) N-Nitroso compounds in the diet. Mutat Res 443:129-138

45. Dahlquist G (1998) The aetiology of type 1 diabetes: an epidemiological perspective. Acta Paediatr Suppl 425:5-10

46. Ito M, Kondo Y, Nakatani A, Naruse A (1999) New model of progressive non-insulin-dependent diabetes mellitus in mice induced by streptozotocin. Biol Pharm Bull 22: 988-989

47. Portha B, Blondel O, Serradas P et al. (1989) The rat models of non-insulin dependent diabetes induced by neonatal streptozotocin. Diabet Metab 15:61-75

48. Piercy V, Toseland CD, Turner NC (1998) Potential benefit of inhibitors of advanced glycation end products in the progression of type II diabetes: a study with aminoguanidine in C57/BLKsJ diabetic mice. Metabolism 47:1477-1480

49. Hofmann SM, Dong HJ, Li Z et al. (2002) Improved insulin sensitivity is associated with restricted intake of dietary glycoxidation products in the $\mathrm{db} / \mathrm{db}$ mouse. Diabetes 51: 2082-2089

50. Vlassara H, Cai W, Crandall J et al. (2002) Inflammatory mediators are induced by dietary glycotoxins, a major risk factor for diabetic angiopathy. Proc Natl Acad Sci USA 99:15596-15601

51. Koschinsky T, He CJ, Mitsuhashi T et al. (1997) Orally absorbed reactive glycation products (glycotoxins): an environmental risk factor in diabetic nephropathy. Proc Natl Acad Sci USA 94:6474-6479

52. Hua NW, Stoohs RA, Facchini FS (2001) Low iron status and enhanced insulin sensitivity in lacto-ovo vegetarians. Br J Nutr 86:515-519

53. Tuomainen TP, Nyyssonen K, Salonen R et al. (1997) Body iron stores are associated with serum insulin and blood glucose concentrations. Population study in 1,013 eastern Finnish men. Diabetes Care 20:426-428

54. Salonen JT, Tuomainen TP, Nyyssonen K, Lakka HM, Punnonen K (1998) Relation between iron stores and noninsulin dependent diabetes in men: case-control study. BMJ 317:727

55. Borel MJ, Beard JL, Farrell PA (1993) Hepatic glucose production and insulin sensitivity and responsiveness in iron-deficient anemic rats. Am J Physiol 264:E380-E390

56. Farrell PA, Beard JL, Druckenmiller M (1988) Increased insulin sensitivity in iron-deficient rats. J Nutr 118:11041109

57. Krebs M, Brehm A, Krssak M et al. (2003) Direct and indirect effects of amino acids on hepatic glucose metabolism in humans. Diabetologia 46:917-925 